\title{
ORIGINAL
}

ARTICLES

\section{The Efficacy of an Antioppression Curriculum for Health Professionals}

Diana Wu, MD; Lamercie Saint-Hilaire, MD; Andrew Pineda; Danielle Hessler, PhD; George Saba, PhD; René Salazar, MD; J. Nwando Olayiwola, MD, MPH

BACKGROUND AND OBJECTIVES: Health professionals increasingly recognize the role that social determinants play in health disparities. However, little focus is placed on how health care professionals themselves contribute to disparities through biased care. We have developed a curriculum based on an antioppression framework which encourages health professionals to evaluate their biases and combat health care disparities through an active process of allyship.

METHODS: Teaching methods emphasize skill building and include lectures, guided reflections, and facilitated discussions. Pre- and postsurveys were administered to assess participants' confidence level to recognize unconscious bias and to be an ally to colleagues, patients, and staff. In total, we conducted 20 workshops with a total of $\mathbf{4 6 8}$ participants across multiple disciplines.

RESULTS: The survey response rate was $80 \%$. Using a paired $t$-test, the mean difference in the pre- and postsurveys revealed a statistically significant improvement across all measures. Participants showed the greatest improvements (large effect size $d>0.8$ ) in their understanding of the process of allyship, their ability to describe strategies to address, assess, and recognize unconscious bias, and their knowledge of managing situations in which prejudice, power, and privilege are involved.

CONCLUSIONS: Results show that an antioppression curriculum can enhance health professionals' confidence in addressing bias in health care through allyship. For those who value social justice and equity, moving from the role of bystander to a place of awareness and solidarity allows for one's behaviors to mirror these values. Allyship is an accessible tool that all health professionals can use in order to facilitate this process.

(Fam Med. 2019;51(X):pp-p.)

doi: 10.22454/FamMed.2018.227415

$\mathbf{H}$ ealth professionals increasingly recognize the role that social determinants of health (SDH) play in fostering and maintaining health disparities. However, SDH is only one category of factors contributing to these differences. Other factors include patient access and health care disparities, which are differences in the delivery of health care. Although health care disparities have been linked to physicians' unconscious biases, ${ }^{1}$ attempts to reduce health inequities primarily focus on $\mathrm{SDH} .^{2,3}$ Such a limited focus risks reinforcing stereotypes and assigning culpability to marginalized communities for the disparities they experience. As a result, some health practitioners may absolve themselves of complicity, while others may be left disheartened and without skills for intervention.

Unconscious bias, also known as implicit bias, is defined as social stereotypes about certain groups of people that individuals form outside their own conscious awareness. ${ }^{4,5} \mathrm{Ev}$ ery individual holds unconscious biases, and extensive research has shown that biases among health care professionals can influence their behaviors and judgments. ${ }^{1,6-9}$ One study showed that medical students rated black patients as more likely than white patients to engage in unprotected sex at increased frequency if prescribed preexposure prophylaxis (PrEP) for HIV infection. This, in turn, was associated with reduced willingness to prescribe PrEP, even though black men who have sex with men report greater condom use and fewer sex partners. ${ }^{10}$ Similarly, in simulated cases of patients with chest pain, physicians were less likely to refer black women for angiography, although heart disease is the leading cause of death for African American women. ${ }^{11,12}$ Another study revealed that greater prowhite

From the University of California San Francisco Family and Community Medicine Department (Drs Wu, Saint-Hilaire, Hessler, Saba, and Olayiwola); San Francisco State University (Mr Pineda); and the University of Texas at Austin Dell Medical School (Dr Salazar). 
biases were associated with a greater inclination to prescribe pain medication for white children compared to black children. ${ }^{13}$ Biased perceptions and disparities of care have also been documented with other marginalized groups, including obese,${ }^{14}$ disabled, ${ }^{15}$ and transgender patients. ${ }^{16}$

Unconscious bias not only adversely contributes to health and health care disparities, but it also affects the training and careers of health care professionals from marginalized groups. ${ }^{17,18}$ Compared to their nonminority peers, medical students who are racial minorities report five times higher odds of experiencing racial discrimination, feelings of isolation, and subsequent lower mental quality of life. ${ }^{19}$ Furthermore, in faculty positions, minority health professionals face the "minority tax", which refers to disparities in evaluation and promotion while bearing the burden of diversity efforts. ${ }^{20}$ Cultivating a diverse workforce increases access to care in underserved communities ${ }^{21}$ and can better prepare all health professionals to eliminate health care disparities in diverse patient populations..$^{22}$

Given the impact of bias, health professionals need skills in recognizing and addressing bias to mitigate the effects on our trainees, colleagues, and patients. However, medical education and health care training currently lacks an emphasis on this skill set. A number of factors contribute to this gap. A focus exclusively on the biomedical model ${ }^{23}$ without a formal engagement with public health, anthropology, and other social sciences creates a dearth of knowledge in structural oppression and the bias it breeds. Thus, health care is abstracted from the social contexts from which both provider and patient emerge. Even if individual health care professionals are knowledgeable, institutional support is needed to facilitate constructive discourse and enact broad change. Without foundational knowledge and institutional policies, trainees and providers can be subject to a "silent curriculum" of the health care system, in which biased behaviors and values are internalized and perpetuated. ${ }^{24}$ Many institutions struggle to promote change due to lack of skilled faculty, competing priorities for medical education, and varied levels of interest. While some medical schools and residency programs have introduced the topic of unconscious bias into formal curricula, ${ }^{25}$ clear frameworks to actively address bias are often lacking. Specifically, previous curriculum and interventions in the past differ in that they either focus on a single issue such as privilege, ${ }^{26}$ or they are created for a single audience. $^{27}$

To address these gaps, we created a curriculum that is grounded in a formal framework of antioppression, includes multiple foci and types of activities, is designed for interdisciplinary audiences, and introduces the process of allyship as a key concept in achieving health equity. We tested the hypothesis that an antioppression curriculum could increase the confidence of health care professionals to address unconscious bias through the process of allyship.

\section{Methods}

\section{Curriculum}

We developed a curriculum for health care professionals and trainees to reflect upon and challenge unconscious biases through an antioppressive framework, ${ }^{23}$ which promotes dignity and empowerment for peoples who have experienced marginalization. Critical social justice theory, ${ }^{28}$ defined as an analytical inquiry of structural oppression, is incorporated to emphasize self-reflection, understanding one's place in oppressive structures, and actively working toward change. We address oppression on institutional, interpersonal, and internalized levels, adapting Dr Camara P. Jones's Tripartite Model of Racism. ${ }^{29}$ We introduce the strategy of allyship, which is "an active, consistent, and arduous practice of unlearning and re-evaluating, in which a person of privilege seeks to operate in solidarity with a marginalized group." 30 Through allyship, this curriculum encourages health professionals to take ownership of the complicit nature of oppression and offers them strategies to become agents for change.

Given the sensitive nature of the content, we deliberately use a nonjudgmental and compassionate tone. As opposed to creating a safe space where painful statements are avoided, we aim to create a brave space ${ }^{31}$ founded on courage, vulnerability, reciprocity, and respect. We model empathy for all experiences and encourage participants to be compassionate to themselves and others, including individuals with whom they disagree.

Our teaching style is based in the power-sharing, egalitarian principles of andragogy or adult learning. ${ }^{32}$ Andragogy uses participants' reservoirs of experience as a learning resource and promotes self-direction and problem-solving. In practice, we set a conversational and nonhierarchical tone with spatial, visual, and verbal cues to encourage participants to share their experiences. While we use didactic, lecture-style facilitation, we emphasize group activities, guided discussion, storytelling, and reflection on historical and current events.

Our curriculum is delivered in a workshop format that consists of three sections: (1) an overview of unconscious bias, (2) an introduction to allyship, and (3) vignettes, in which participants use cases to practice skills introduced in the previous sections (Table 1).

In the unconscious bias section, participants explore the universality of unconscious bias to the human experience. We demonstrate this through interactive activities, such as the Stroop Test, ${ }^{33}$ as well as psychology theory and bias research. We then show evidence of unconscious bias in multiple fields, including health care. Prior to the workshop, participants are asked to take the Implicit Association Test, ${ }^{34}$ which measures implicit attitudes by the strength of associations between different groups and characteristics. 
Our main objective is to openly discuss and normalize the emotions experienced when facing one's own unconscious biases. We complete this section of the workshop by summarizing current research on ways to combat unconscious bias, including bias literacy ${ }^{35}$ and emotional regulation. ${ }^{36-38}$

During the second part of the workshop, we present allyship as an overarching strategy that prioritizes consciousness-raising, capacity-building, and behavioral changes. For participants who may not identify with the narrative of "oppressor" or "oppressed," allyship provides an accessible and active role to combat social injustices. Historical and contemporary examples are studied to illustrate the core components of allyship_privilege, awareness, and action. We highlight cultural appropriation $^{39}$ to explore the nuances in privilege and power dynamics. The concept of intersectionality ${ }^{40}$ is introduced to underscore the ubiquitous complexity of shared marginalized and privileged experiences. At the end of this section, we offer our Step Up/Step Back Model to determine when to either speak out for those unable to (Step Up) or support the marginalized to speak out for themselves (Step Back).

The final workshop section is vignette-based, involving small group activity, followed by large group discussion. Each vignette situates the participants as bystanders, who are confronted with a challenging interaction involving bias, power, and privilege. This intentional positioning as a bystander allows everyone to participate while maintaining selfintegrity, ${ }^{41}$ even if participants may deny biased behavior or experience of marginalization. Using a group activity that we developed, called Power Mapping, participants explore interpersonal and structural power dynamics, discuss possible courses of action, and practice acts of allyship. Vignettes address patient care topics, such as transphobia, overuse of force, and reproductive coercion, in addition to medical education and training topics, such as impostor syndrome ${ }^{42-43}$ and the model minority myth..$^{44}$

Our aim is to humanize all the characters in the vignettes, showing how biases are not only possible but common. Participants identify barriers to allyship, such as role morality and diffusion of responsibility. ${ }^{45}$ Then, they practice antioppressive strategies, such as deconstruction of hierarchical relationships, emotional regulation, and egalitarian communication..$^{23}$ We close the workshop with participants making a commitment to work toward allyship.

\section{Participants}

This curriculum is designed specifically for health care professionals, and participants have included medical and nursing students, residents and faculty, nurses and medical assistants, and research and administrative staff (Table 2). The departments and fields encompassed family medicine, obstetrics, midwifery, abortion care, integrative medicine, psychiatry, emergency medicine, and surgical specialties. Two of the authors (D.W., L.S.) were the sole facilitators of each workshop.

\section{Setting}

Originally designed for a family medicine resident seminar, the workshop received overwhelmingly positive feedback. Subsequently, other departments, clinics, and programs requested it. All sessions, except for three, were mandatory. Further details are presented in Table 2.

\section{Measures}

We developed pre- and postsurveys to evaluate the workshop's capacity to improve awareness of bias and address it through allyship. The survey contains eight measures which reflect the overall curriculum objectives (Table 3). Additionally, participants indicate their previous level of training in unconscious bias and allyship, comment on learning goals in presurveys, and provide feedback in postsurveys. A Likert scale was used (ranging from $1=$ strongly disagree to $5=$ strongly agree) to rate participants' levels of prior training in bias and allyship, confidence level in understanding, recognizing, and addressing unconscious bias, as well as confidence level in being an ally to patients, colleagues, and staff. To pair pre- and postsurveys, anonymous alphanumeric identifiers were created.

\section{Procedures}

We conducted 20 workshops between July 2015 and January 2018. Workshops on average lasted 3 hours (ranging 1.5-4 hours), depending on depth of discussion and time allotment. Participants received paper pre- and postsurveys immediately prior to and following the workshop. Exceptions include the OB/Midwifery Department and Southwestern Women's Surgery Center (SWSC), in which a trial of online presurveys were sent 1 week prior to the workshop. Paper surveys were provided to those who did not complete the online version. For SWSC, we also conducted a trial of online postsurveys, sent immediately following the workshop. Given the significant decrease in response rate, online surveys were not further attempted. The first large group workshop with more than 20 participants (Family and Community Medicine Department Faculty Meeting) revealed an unanticipated decrease in response rate. In subsequent large groups, we actively encouraged postsurvey completion to ensure high response rates.

\section{Data Analysis}

For all eight survey measures, preand postworkshop scores were compared using a paired $t$-test with pairwise exclusion to determine any statistically significant mean differences. Any presurvey without a postsurvey pair, or vice versa, constituted unpaired data and were excluded from the data set. Cohen's $d$ assessed effect sizes for pre- and postworkshop differences.

To investigate the influence of previous training on pre- to postscore, responses to survey items one and 
two were divided to create more balanced group sizes based on self-identified effectiveness of prior training: strongly disagree/disagree, neutral, and agree/strongly agree. A one-way analysis of variance (ANOVA) with Tukey adjustments for pairwise comparisons was conducted to determine if pre- to postmean differences for each survey measure, A-H, were different for groups with varying prior training effectiveness in unconscious bias and in allyship (survey items one and two).

$P$ values $<0.05$ were considered statistically significant. Cohen $d$ values of $>0.2,0.5$, and 0.8 were considered small, medium, and large effect sizes, respectively. Statistical analyses were performed using IBM SPSS Statistics Subscription for Macintosh Version 1.0.0.800. The qualitative presurvey workshop goals and postsurvey feedback were not included in the analysis due to the varying rate and nature of responses. The University of California San Francisco (UCSF) Institutional Review Board granted this study an exemption on April 6, 2016 (\#16-19116).

\section{Results}

A total of 468 participants attended the workshops with a survey response rate of $80 \%$. Figure 1 shows the number of valid pre- and postsurvey pairs. The paired $t$-test analysis revealed a statistically significant improvement in pre- to postsurvey mean scores across all measures, A-H, with a $P$ value $<0.001$ (Figure 1 and Table 3). Participants showed the greatest improvement in preto postscores and a large effect size in survey measures $\mathrm{B}, \mathrm{C}, \mathrm{D}$, and $\mathrm{H}$ ([mean difference, Cohen's $d]$ : $\mathrm{B}[0.99$, $d=1.04], \mathrm{C}[1.09, d=1.18], \mathrm{D}[1.12$, $d=1.13], \mathrm{H}[0.82, d=0.98])$. They showed improvement with moderate effect sizes in survey measures A, E, $\mathrm{F}$, and $\mathrm{G}$ ([mean difference, Cohen's $d]$ : $\mathrm{A}[0.69, d=0.79], \mathrm{E}[0.47, d=0.57]$, $\mathrm{F}[0.46, d=0.60], \mathrm{G}[0.52, d=0.65])$.

\section{History of Prior Training}

The one-way ANOVA demonstrated that for survey item one, all omnibus
$F$ tests were statistically significant $(P<0.001$ A-C; $P<0.01$ D,E,G; $P<0.05$ $\mathrm{F}, \mathrm{H})$. Additionally, for survey item two, all omnibus $F$ tests, with the exception of $\mathrm{A}$ and $\mathrm{B}$, were statistically significant $(P<0.001 \mathrm{D}-\mathrm{G} ; P<0.05$ $\mathrm{C}, \mathrm{H})$.

Tukey post hoc analysis revealed that overall, those who felt that their prior training was not effective (strongly disagree/disagree) benefited more from the workshop than other groups. For survey item one, mean differences of measures A-C, which all address unconscious bias, were significantly greater in the strongly disagree/disagree group compared to the agree/strongly agree group (mean increase disagree group vs agree group, $P$ value: $\mathrm{A}=1.03$ vs 0.51 , $P<0.001 ; \mathrm{B}=1.13$ vs $0.79, P=0.02$; $\mathrm{C}=1.37$ vs $0.86, P<0.001)$. There were also significant group differences between neutral and agree/ strongly agree for survey measures A-C (Figure 2).

For survey item two, mean differences of measures D-G, which all address allyship, were significantly greater in the strongly disagree/disagree group compared to the agree/ strongly agree group (mean increase disagree group vs agree group, $\mathrm{P}$ value: $\mathrm{D}=1.55$ vs $0.83, P<0.001 ; \mathrm{E}=0.82$ vs $0.30, P<0.001 ; \mathrm{F}=0.74$ vs 0.28 , $P<0.001 ; \mathrm{G}=0.87$ vs $0.33, P<0.001)$. There were also significant group differences between neutral and agree/strongly agree for measures D, F, G and between strongly-disagree/ disagree and neutral for measure $\mathrm{E}$ (Figure 2).

\section{Discussion}

Our findings show that this curriculum based on an antioppression framework improves health professionals' overall confidence in addressing bias in health care through allyship. Although every measure showed an improvement overall, the levels of improvement varied. Participants showed the greatest improvements in their understanding of the process of allyship, their ability to describe strategies to recognize, assess, and address unconscious bias, and their knowledge of managing situations in which prejudice, power, and privilege are involved. This is a meaningful finding given that in a previous study, participants were unable to recognize implicit bias after one training session. ${ }^{46}$ Participants showed moderate improvements in understanding unconscious bias concepts and in being an ally to colleagues, patients, and team members/staff, which demonstrates the complexity in the lifelong work of allyship. This is indicative of the relative ease of memorizing new terminology and strategies compared to applying learned skills in practice $^{47}$ and also aligns with previous research on the need to practice addressing implicit bias over time. ${ }^{48}$

Our findings also showed that while participants with prior training in unconscious bias and allyship benefit from the curriculum, those who identified lack of effective prior training in bias or allyship showed the greatest improvements in the survey measures addressing bias and allyship, respectively. Even those who identified effective prior training showed improvements in all survey measures.

Qualitative feedback given in the postsurvey comments showed overall positive responses, calling the curriculum an "exciting approach to discussing theoretical frameworks for actually responding to acts of unconscious bias." The vignettes section received substantial positive feedback, and participants frequently requested additional time for practicing skills and "more vignettes to practice more strategies and scenarios."

\section{Limitations}

The curriculum evaluation contains three main limitations. First, participant demographic information was not solicited, because it could compromise anonymity and confidentiality for small workshops. Second, our evaluation assesses only the first two levels of the Kirkpatrick Evaluation Model by soliciting reactions and perceived acquired knowledge, but does not measure actual behavioral 
Figure 1: Comparison of the Mean Values of the Pre- and Postworkshop Survey Results (***P<0.001)

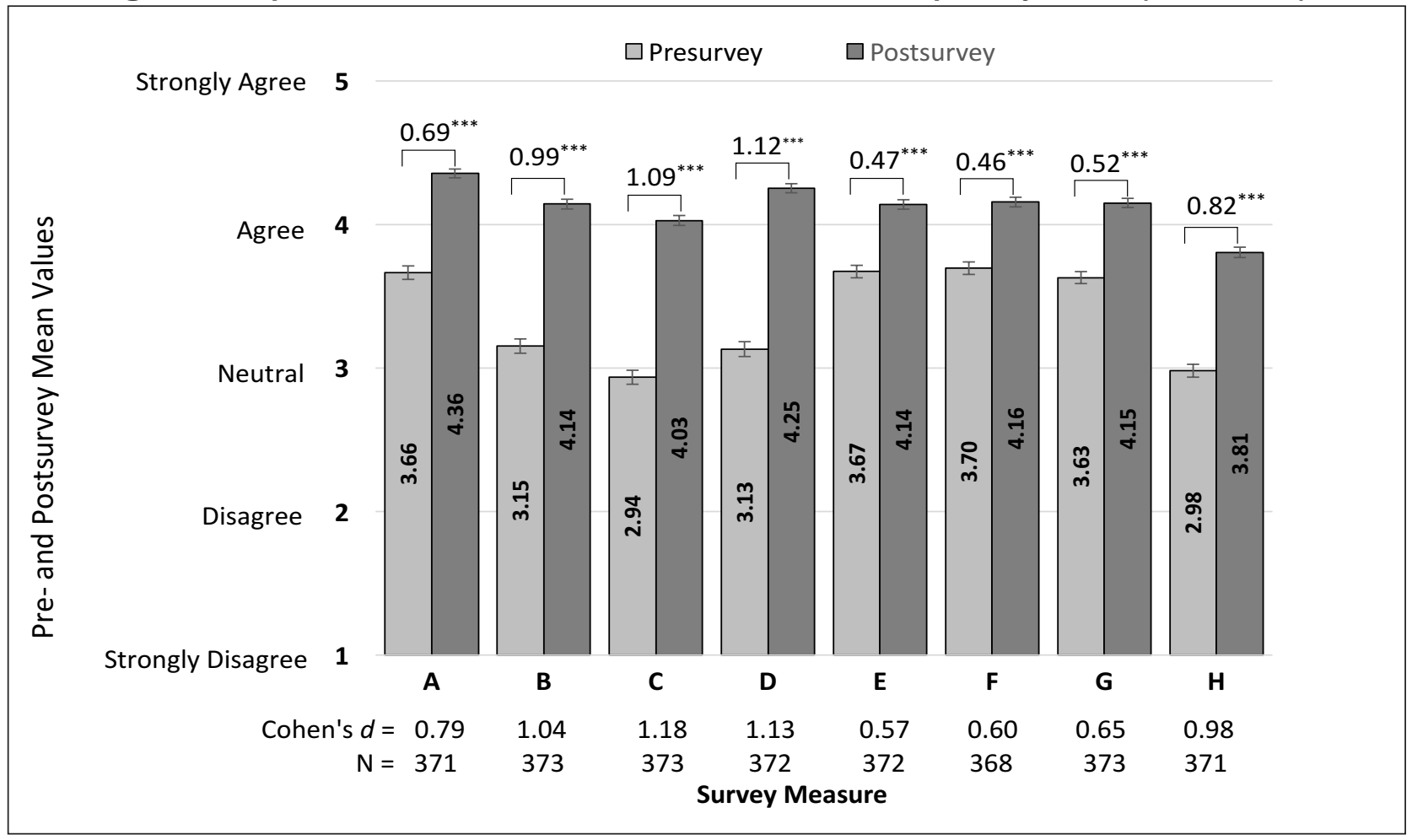

Figure 2: History of Training in Unconscious Bias and Allyship and its Effect on Workshop Survey Results

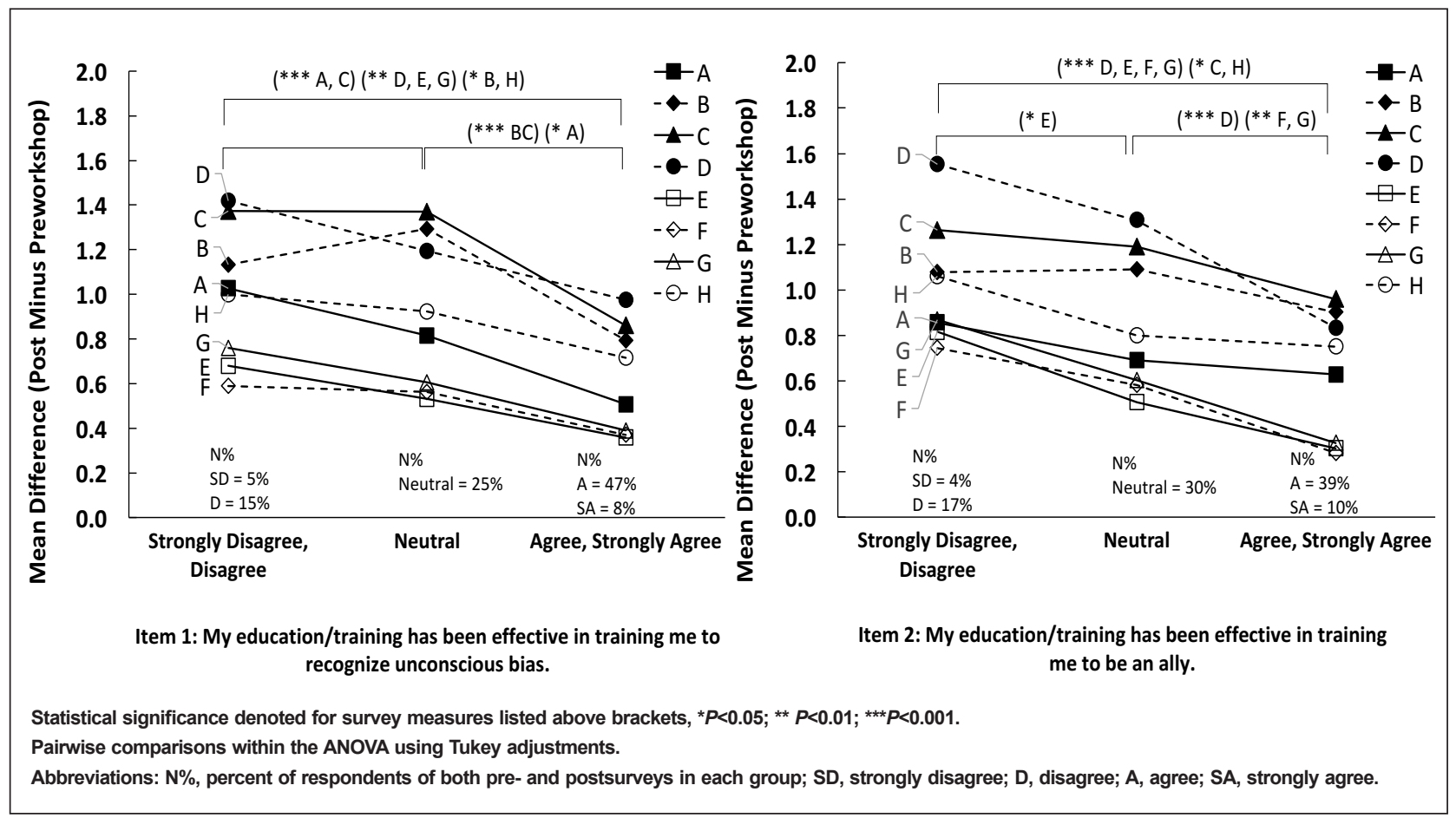


Table 1: Unconscious Bias and Allyship Workshop

\begin{tabular}{|c|c|c|c|}
\hline Section & Themes & Topics and Examples & Teaching Style \\
\hline \multirow{5}{*}{$\begin{array}{l}\text { Unconscious bias } \\
(0.5-1 \mathrm{hr})\end{array}$} & Definition & $\begin{array}{l}\text { Mindbugs, Stroop Test, misinformation } \\
\text { effect }\end{array}$ & $\begin{array}{l}\text { Guided discussion, } \\
\text { didactic, group activity, } \\
\text { storytelling }\end{array}$ \\
\hline & Bias in multiple fields & Gender bias, labor market discrimination & Didactic \\
\hline & $\begin{array}{l}\text { Implicit association test and } \\
\text { effects on healthcare }\end{array}$ & $\begin{array}{l}\text { Patient experience, medical decision- } \\
\text { making, dissociation, multidimensional } \\
\text { consciousness }\end{array}$ & $\begin{array}{l}\text { Didactic, quotes, group } \\
\text { discussion, reflection }\end{array}$ \\
\hline & Hidden discrimination & In group vs out group & Storytelling \\
\hline & Combating bias & $\begin{array}{l}\text { Bias literacy, emotional regulation, } \\
\text { hiring/evaluating practices, culture } \\
\text { change }\end{array}$ & Didactic \\
\hline \multirow{4}{*}{ Allyship (0.5-1 hr) } & Definition & $\begin{array}{l}\text { Lessons from } 1968 \text { Summer Olympics } \\
\text { demonstration }\end{array}$ & $\begin{array}{l}\text { Guided discussion, } \\
\text { reflection on historical } \\
\text { event, storytelling }\end{array}$ \\
\hline & Power and privilege & $\begin{array}{l}\text { Cultural appropriation, cultural } \\
\text { exchange, cultural assimilation, } \\
\text { invisibility of Native Americans, } \\
\text { intersectionality, privilege distress }\end{array}$ & Guided discussion, quotes \\
\hline & How to be an ally & $\begin{array}{l}\text { Best practices and common mistakes, } \\
\text { lessons from \#BlackLivesMatter } \\
\text { demonstration }\end{array}$ & $\begin{array}{l}\text { Guided discussion, } \\
\text { didactic, reflection on } \\
\text { recent event }\end{array}$ \\
\hline & Step Up/Step Back model & Strategies for empowerment & Didactic \\
\hline Vignettes $(2-3 \mathrm{hrs})$ & $\begin{array}{l}\text { Religious bias } \\
\text { - Islamophobia } \\
\text { Racial bias } \\
\text { - } \quad \text { Minority tax } \\
\text { - } \quad \text { Model minority myth } \\
\text { - } \quad \text { Overuse of force } \\
\text { Gender and sexuality bias } \\
\text { - } \quad \text { Misgendering } \\
\text { - Transphobia }\end{array}$ & $\begin{array}{l}\text { Reproductive justice } \\
\text { - } \quad \text { Forced sterilization } \\
\text { - } \quad \text { Use of "Utox" in pregnancy } \\
\text { - } \quad \text { Sex-selective abortion bans } \\
\text { - } \quad \text { Contraceptive coercion } \\
\text { Disability bias } \\
\text { Language discordance } \\
\text { Medical education/training } \\
\text { - Microaggressions } \\
\text { - Imposter syndrome } \\
\text { - } \quad \text { Medical hierarchy }\end{array}$ & $\begin{array}{l}\text { Small group discussion, } \\
\text { large group guided } \\
\text { discussion/reflection, group } \\
\text { activity (Power Mapping), } \\
\text { skill building }\end{array}$ \\
\hline
\end{tabular}

Table 2: Workshop Descriptions and Settings

\begin{tabular}{|c|l|c|c|c|l|l|}
\hline Date & \multicolumn{1}{|c|}{ Workshop } & $\begin{array}{c}\text { Respondents } \\
\text { to Both } \\
\text { Pre- and } \\
\text { Postsurvey }\end{array}$ & $\begin{array}{c}\text { Workshop } \\
\text { Participants }\end{array}$ & $\begin{array}{c}\text { Response } \\
\text { Rate }\end{array}$ & \multicolumn{1}{|c|}{$\begin{array}{c}\text { Training Setting } \\
\text { Duration } \\
\text { (hours) }\end{array}$} \\
\hline $7 / 1 / 15$ & UCSF FCM Resident Seminar & 6 & 6 & $100 \%$ & Residents \\
\hline $7 / 13 / 15$ & FCM SUHLA Leadership & 5 & 5 & $100 \%$ & $\begin{array}{l}\text { Residents/medical } \\
\text { students }\end{array}$ \\
\hline $9 / 8 / 15$ & PRIME-US at JMP & 17 & 17 & $100 \%$ & Medical students & 2 \\
\hline $9 / 17 / 15$ & $\begin{array}{l}\text { FCM Department Faculty } \\
\text { Meeting }\end{array}$ & 27 & 41 & $66 \%$ & Faculty & 2.5 \\
\hline $9 / 24 / 15$ & UCSF FCM Resident Seminar & 6 & 8 & $75 \%$ & Residents \\
\hline $2 / 25 / 16$ & $\begin{array}{l}\text { Contra Costa FMRP Resident } \\
\text { Seminar }\end{array}$ & 10 & 10 & $100 \%$ & Residents \\
\hline $5 / 6 / 16$ & Osher Center Retreat & 42 & 46 & $91 \%$ & Clinic retreat & 2.5 \\
\hline $8 / 11 / 16$ & UCSF FCM Resident Seminar & 8 & 8 & $100 \%$ & Residents \\
\hline
\end{tabular}

(continued on next page) 
Table 2, Workshop Descriptions and Settings (continued)

\begin{tabular}{|c|c|c|c|c|c|c|}
\hline Date & Workshop & $\begin{array}{l}\text { Respondents } \\
\text { to Both } \\
\text { Pre- and } \\
\text { Postsurvey }\end{array}$ & $\begin{array}{l}\text { Workshop } \\
\text { Participants }\end{array}$ & $\begin{array}{l}\text { Response } \\
\text { Rate }\end{array}$ & Training Setting & $\begin{array}{l}\text { Duration } \\
\text { (hours) }\end{array}$ \\
\hline $10 / 5 / 16$ & ZSFG Urgent Care Center & 27 & 31 & $87 \%$ & Clinic retreat & 4 \\
\hline $10 / 11 / 16$ & $\begin{array}{l}\text { UCSF Health and Society } \\
\text { Pathway }\end{array}$ & 10 & 10 & $100 \%$ & Medical students & 2 \\
\hline $11 / 17 / 16$ & UCSF FCM Resident Seminar & 6 & 6 & $100 \%$ & Residents & 4 \\
\hline $11 / 19 / 16$ & CREATE Program & 9 & 11 & $82 \%$ & Residents $^{\mathrm{v}}$ & 3 \\
\hline $11 / 25 / 16$ & UCSF Psychiatry Faculty Retreat & 10 & 14 & $71 \%$ & Conference $^{\mathrm{v}}$ & 1.5 \\
\hline $2 / 14 / 17$ & $\begin{array}{l}\text { ZSFG OB and Midwifery } \\
\text { Department }\end{array}$ & 28 & 33 & $85 \%$ & $\begin{array}{l}\text { Department } \\
\text { seminar }\end{array}$ & 4 \\
\hline $2 / 28 / 17$ & $\begin{array}{l}\text { ZSFG OB and Midwifery } \\
\text { Department }\end{array}$ & 19 & 23 & $83 \%$ & $\begin{array}{l}\text { Department } \\
\text { seminar }\end{array}$ & 4 \\
\hline $4 / 20 / 17$ & UCSF Transitional Clerkship & 107 & 136 & $79 \%$ & Medical Students & 4 \\
\hline $5 / 6 / 17$ & CIR National Conference & 10 & 13 & $77 \%$ & Conference $^{\mathrm{v}}$ & 2.5 \\
\hline $7 / 31 / 17$ & $\begin{array}{l}\text { Southwestern Women's Surgery } \\
\text { Center }\end{array}$ & 13 & 36 & $36 \%$ & Clinic meeting & 2.5 \\
\hline $10 / 5 / 17$ & $\begin{array}{l}\text { UCSF Health and Society } \\
\text { Pathway }\end{array}$ & 8 & 8 & $100 \%$ & Medical students & 3 \\
\hline \multirow[t]{2}{*}{$1 / 25 / 18$} & UCSF FCM Resident Seminar & 6 & 6 & $100 \%$ & Residents & 4 \\
\hline & Total & 374 & 468 & $80 \%$ & & \\
\hline
\end{tabular}

Abbreviations: CIR, Committee of Interns and Residents; CREATE, Continuing Reproductive Education for Advanced Training Efficacy; FCM, Family and Community Medicine; FMRP, family medicine residency program; JMP, Joint Medical Program; PRIME-US, Program in Medical Education for the Urban Underserved; SUHLA, Summer Urban Health and Leadership Academy; UCSF, University of California, San Francisco; ZSFG, Zuckerberg San Francisco General Hospital; ${ }^{\mathrm{v}}$, voluntary session.

Table 3: Pre- and Postworkshop Survey Measures

\begin{tabular}{|c|l|}
\hline Item & \multicolumn{1}{|c|}{ Statement } \\
\hline $1^{\text {a }}$ & My education/training has been effective in training me to recognize unconscious bias. \\
\hline $2^{\text {a }}$ & My education/training has been effective in training me to be an ally. \\
\hline A & I am confident in my understanding of unconscious bias concepts. \\
\hline B & I can describe a strategy to assess and/or recognize unconscious bias. \\
\hline C & I can describe a strategy to address unconscious bias. \\
\hline D & I am confident in my understanding of the process of allyship. \\
\hline E & I am confident in my ability to be an ally to my colleagues. \\
\hline F & I am confident in my ability to be an ally to my patients. \\
\hline G & I am confident in my ability to be an ally to team members/staff. \\
\hline H & $\begin{array}{l}\text { I know how to effectively manage uncomfortable situations in which forces such as prejudice, power, and privilege } \\
\text { are involved. }\end{array}$ \\
\hline
\end{tabular}

${ }^{\text {a }}$ Items 1 and 2 were included only in the preworkshop surveys to measure participants' history of effective training in unconscious bias and in allyship. 
change or downstream effects (levels 3 and 4). Another limitation was differences in time allotted for the workshop. Ultimately, we recommended 3 hours as the minimum time allotment to cover all topics.

\section{Next Steps}

Teaching this curriculum in more settings with a larger sample size would allow for the collection of demographic data to analyze the relationship between survey responses and participants' roles, levels of training, and other demographics, such as race and gender. Additionally, collecting 6-month and 1-year postsurveys would reveal the duration of the workshop's positive effects.

Future studies should evaluate whether such programs improve the learning environment, interprofessional team dynamics, patient care, health disparities, patient satisfaction, and satisfaction of health professionals. Educational models, which use direct clinical observation or standardized patients, should assess health care trainees' ability to incorporate these skills into clinical care.

Lastly, the authors envision a facilitation guide and a comprehensive train-the-trainer program that would empower academic institutions and health care settings to offer the workshop independently and equip health care educators with solutionoriented approaches.

\section{Conclusion}

Health professionals consistently endorse egalitarian goals based in justice and fairness, ${ }^{49-50}$ however history and research have proven that when we continue the status quo, we become complicit with oppression. Our results show that an antioppression curriculum, based on dignity, empowerment, and egalitarianism, provides necessary space for skill building to actively address injustices in health care. Providing an accessible process of action is of utmost importance, and allyship allows for the alignment of behaviors with good intentions. As more academic institutions and health care settings incorporate cultural humility, unconscious bias, and structural competency into their curriculum, allyship is an active and accessible next step in addressing health care disparities.

ACKNOWLEDGMENTS: The authors acknowledge Diana Coffa, MD, Kevin Grumbach, MD and UCSF Family and Community Medicine Department; Renee Navarro, PharmD MD and the UCSF Office of Diversity and Outreach; Howard Pinderhughes, $\mathrm{PhD}$; and LaShaya Howie, MA for their support and assistance in the creation of this curriculum, research, and manuscript.

Financial support for this study was provided by UCSF Dean's Diversity Fund.

Presentations: Presented at the University of California, San Francisco Family and Community Medicine Thomas Bodenheimer Symposium in San Francisco, CA on September 26, 2015; Society of Teachers of Family Medicine Annual Spring Conference in Minneapolis, MN on May 1,2016; University of California, San Francisco Family and Community Medicine Jonathan Rodnick Colloquium in San Francisco, CA on June 2, 2016.

CORRESPONDING AUTHOR: Address correspondence to Dr Diana Wu, University of California San Francisco Family and Community Medicine Department, 995 Potrero Ave Ward 83, San Francisco, CA 94110. 919-892-9122. BiasAndAllyship@gmail.com.

\section{References}

1. Stone J, Moskowitz GB. Non-conscious bias in medical decision making: what can be done to reduce it? Med Educ. 2011;45(8):768-776.

2. Purnell TS, Calhoun EA, Golden SH, et al. Achieving Health Equity: Closing The Gaps In Health Care Disparities, Interventions, And Research. Health Aff (Millwood) 2016;35(8):1410-1415.

3. Thornton RLJ, Glover CM, Cené CW, Glik DC, Henderson JA, Williams DR. Evaluating Strategies For Reducing Health Disparities By Addressing The Social Determinants Of Health. Health Aff (Millwood). 2016;35(8):14161423.

4. Fiske ST, Taylor SE. Social Cognition. 2nd ed. New York, NY: McGraw Hill; 1991.

5. Valian V. Why So Slow? The Advancement of Women. Cambridge: The MIT Press; 1998.

6. Hoffman KM, Trawalter S, Axt JR, Oliver MN. Racial bias in pain assessment and treatment recommendations, and false beliefs about biological differences between blacks and whites. Proc Natl Acad Sci USA. 2016;113(16):42964301.

7. Hampton SB, Cavalier J, Langford R. The influence of race and gender on pain management: A systematic literature review. Pain Manag Nurs. 2015;16(6):968-977.
8. Harris LH, Wolfe T. Stratified reproduction, family planning care and the double edge of history. Curr Opin Obstet Gynecol. 2014;26(6):539-544.

9. Green AR, Carney DR, Pallin DJ, et al. Implicit bias among physicians and its prediction of thrombolysis decisions for black and white patients. J Gen Intern Med. 2007;22(9):12311238.

10. Calabrese SK, Magnus M, Mayer KH, et al. Putting PrEP into Practice: Lessons Learned from Early-Adopting U.S. Providers' Firsthand Experiences Providing HIV Pre-Exposure Prophylaxis and Associated Care. PLoS One. 2016;11(6):e0157324.

11. Heron M. Deaths: leading causes for 2008. Natl Vital Stat Rep. 2012;60(6):1-94.

12. Schulman KA, Berlin JA, Harless W, et al. The effect of race and sex on physicians' recommendations for cardiac catheterization. N Engl J Med. 1999;340(8):618-626.

13. Sabin JA, Greenwald AG. The influence of implicit bias on treatment recommendations for 4 common pediatric conditions: pain, urinary tract infection, attention deficit hyperactivity disorder, and asthma. Am J Public Health. 2012;102(5):988-995.

14. Persky S, Eccleston CP. Medical student bias and care recommendations for an obese versus non-obese virtual patient. Int J Obes. 2011;35(5):728-735.

15. Kripke C. Avoiding unconscious bias about disability when discussing goals of care. Am Fam Physician. 2017;96(3):192-195.

16. Grant JM, Mottet LA, Tanis J, Harrison J, Herman J, Keisling M. Injustice at every turn: a report of the National Transgender Discrimination Survey. Washington, DC: National Center for Transgender Equality and National Gay and Lesbian Task Force 2011. http://www. thetaskforce.org/static html/downloads/reports/ reports/ntds_full.pdf. Accessed February 20, 2018.

17. Boatright D, Ross D, O'Connor P, Moore E, Nunez-Smith M. Racial disparities in medical student membership in the Alpha Omega Alpha Honor Society. JAMA Intern Med. 2017;177(5):659-665

18. Boiko JR, Anderson AJM, Gordon RA. Representation of women among academic grand rounds speakers. JAMA Intern Med. 2017;177(5):722-724

19. Dyrbye LN, Thomas MR, Eacker A, et al. Race, ethnicity, and medical student wellbeing in the United States. Arch Intern Med. 2007;167(19):2103-2109.

20. Rodríguez JE, Campbell KM, Pololi LH. Addressing disparities in academic medicine: what of the minority tax? BMC Med Educ. 2015;15(1):6

21. Walker KO, Moreno G, Grumbach K. The association among specialty, race, ethnicity, and practice location among California physicians in diverse specialties. J Natl Med Assoc. 2012;104(1-2):46-52

22. Saha S, Guiton G, Wimmers PF, Wilkerson L. Student body racial and ethnic composition and diversity-related outcomes in US medical schools. JAMA. 2008;300(10):1135-1145. 
23. Larson G. Anti-oppressive practice in mental health. J Prog Hum Serv. 2008;19(1):39-54.

24. Brooks KC. A piece of my mind. A silent curriculum. JAMA. 2015;313(19):1909-1910.

25. Sukhera J, Watling C. A Framework for integrating implicit bias recognition into health professions education. Acad Med 2018;93(1):35-40.

26. Holm AL, Rowe Gorosh M, Brady M, WhitePerkins D. Recognizing Privilege and Bias: An Interactive Exercise to Expand Health Care Providers' Personal Awareness. Acad Med. 2017;92(3):360-364.

27. Schultz PL, Baker J. Teaching Strategies to Increase Nursing Student Acceptance and Management of Unconscious Bias. J Nurs Educ. 2017;56(11):692-696.

28. Sensoy Ö, DiAngelo R. Is everyone really equal?:an introduction to key concepts in social justice education. New York, NY: Teachers College Press; 2012.

29. Jones CP. Levels of racism: a theoretic framework and a gardener's tale. Am J Public Health. 2000;90(8):1212-1215.

30. The Anti-Oppression Network. Allyship. https:// theantioppressionnetwork.com/allyship/. Accessed July 1, 2015.

31. Arao B, Clemens K. From Safe Spaces to Brave Spaces: A New Way to Frame Dialogue Around Diversity and Social Justice. In: Landreman LM, ed. The Art of Effective Facilitation: Reflections from Social Justice Educators. Sterling, VA: Stylus Publishing, LLC; 2013:135-150.

32. Smith MK. Malcolm Knowles, informal adult education, self-direction and andragogy. The Encyclopedia of Informal Education 2002 http://infed.org/mobi/malcolm-knowlesinformal-adult-education-self-direction-andandragogy/?utm_campaign=elearningindustry. com\&utm_source $=\% 2 \mathrm{Fthe}$-adult-learningtheory-andragogy-of-malcolm-knowles\&utm medium=link. Accessed Feb 10, 2018
33. Scarpina F, Tagini S. The Stroop Color and Word Test. Front Psychol. 2017;8(557):557.

34. Project Implicit. https://implicit.harvard.edu/ implicit. Accessed July 1, 2015.

35. National Academy of Science. Beyond Bias and Barriers: Fulfilling the Potential of Women in Academic Science and Engineering. Washington, DC: The National Academies Press; 2007.

36. Martell RF. Sex bias at work: the effects of attentional and memory demands on performance ratings of men and women. J Appl Soc Psychol. 1991;21(23):1939-1960.

37. Blair IV, Banaji MR. Automatic and controlled processes in stereotype printing. J Pers Soc Psychol. 1996;70(6):1142-1163.

38. Staats C. State of the Science: Implicit Bias Review 2014. http://kirwaninstitute.osu.edu/ wp-content/uploads/2014/03/2014-implicit-bias. pdf. Columbus, OH: Kirwan Institute. Accessed September 18, 2016.

39. Scafidi S. Who Owns Culture?: Appropriation and Authenticity in American Law. Piscataway, NJ: Rutgers University Press; 2005.

40. Crenshaw K. Demarginalizing the intersection of race and sex: a black feminist critique of antidiscrimination doctrine, feminist theory, and antiracist politics. Univ Chic Leg Forum. 1989(1):139-167.

41. Cohen GL, Sherman DK. The psychology of change: self-affirmation and social psychological intervention. Annu Rev Psychol. 2014;65(1):333-371.

42. Henning K, Ey S, Shaw D. Perfectionism, the imposter phenomenon and psychological adjustment in medical, dental, nursing and pharmacy students. Med Educ. 1998;32(5):456-464.

43. Montenegro RE. My Name Is Not "Interpreter". JAMA. 2016;315(19):2071-2072.

44. Chou RS, Feagin JR. The myth of the model minority: Asian Americans facing racism. Boulder, CO: Paradigm Press; 2008.
45. Law Room Training. Intersections: Harassment Prevention Training For 2016. Online seminar. Accessed Sept 2016.

46. Gonzalez CM, Kim MY, Marantz PR. Implicit bias and its relation to health disparities: a teaching program and survey of medical students. Teach Learn Med. 2014;26(1):64-71.

47. Heer R. A model of learning objectives based on a taxonomy for learning, teaching, and assessing: a revision of bloom's taxonomy of educational objectives. Center for Excellence in Learning and Teaching, Iowa State University 2012. http://www.celt.iastate.edu/wp-content/ uploads/2015/09/RevisedBloomsHandout-1.pdf. Accessed February 28, 2018.

48. Byrne A, Tanesini A. Instilling new habits: addressing implicit bias in healthcare professionals. Adv Health Sci Educ Theory Pract. 2015;20(5):1255-1262.

49. Draper C, Louw G. What is medicine and what is a doctor? Medical students' perceptions and expectations of their academic and professional career. Med Teach. 2007;29(5):e100-e107. https://doi.org/10.1080/01421590701481359

50. Banaji MR, Greenwald AG. Blind Spot: Hidden Biases of Good People. New York, NY: Delacorte Press; 2013. 